УДК 930/902(510)

DOI 10.25205/1818-7919-2018-17-4-16-29

\author{
Ван Пэн \\ Институт археологии АОН КНР \\ ул. Ванфуизин, 23, Пекин, Китай \\ kaoguwangpeng@163.com

\section{ВЗАИМОДЕЙСТВИЕ КУЛЬТУР БРОНЗОВОГО И РАННЕГО ЖЕЛЕЗНОГО ВЕКА ЮЖНОЙ СИБИРИ, СИНЬЦЗЯНА И СЕВЕРНОГО КИТАЯ *}

\begin{abstract}
Около 2000 г. до н. э. одна из ветвей европеоидного населения достигла территории современного Синьцзяна, где оставила наиболее ранние свидетельства культуры бронзового века в виде могильника Кэрмуци (Чемурчек). Элементы андроновской культуры широко распространились в западной и центральной части Синьцзяна. Начиная с 1300 г. до н. э. в узорах на керамических и бронзовых изделиях Иньского городища (Иньсюй) возникают формы, которые демонстрируют сходство с карасукской, ирменской, еловской, бегазы-дандыбаевской культурами. Однако сами эти культуры до сих пор не обнаружены на территории Северного Китая. Ситуация, вероятно, объясняется тем, что группа людей за короткий период времени переселилась из Южной Сибири и Северного Казахстана в регион китайской Центральной равнины; очевидно, с этим связано внезапное появление колесниц и лошадей в Иньсюй. Изображения свернувшихся животных, парных и одиночных птиц в нефритовых изделиях культуры Хуншань обнаруживают прямую линию преемственности с культурами Шан и Чжоу, а также с мотивами скифского искусства последующей эпохи.

Ключевые слова: Южная Сибирь, Северный Китай, Синьцзян, бронзовый век, ранний железный век, культурный обмен.
\end{abstract}

Исследования советских археологов, посвященные культурному обмену между Южной Сибирью и территориями Северного Китая и Синьцзяна в бронзовом и раннем железном веках, восходят к 1920-м гг., когда С. А. Теплоухов [1927; 1929] осуществлял комплексное исследование древних культур Минусинской котловины. В 1950-е гг., после визита в Китай С. В. Киселева, в советском археологическом сообществе появился интерес к культурному взаимодействию между двумя регионами. С тех пор число публикаций советских (а затем российских) археологов, обратившихся к данной проблеме, постоянно увеличивалось. Однако их китайские коллеги вследствие малого знакомства с южно-сибирскими материалами и ряда других причин приступили к аналогичным исследованиям только с периода 1980-х гг. (см.: [Ван Пэн, Кэмисалофу, 2013]).

За последние десятилетия российским и китайским археологам удалось прояснить общие контуры решения этих научных проблем. Приведем ряд примеров. Около 2000 г. до н. э. одна из ветвей европеоидного населения проникла в Синьцзян, оставив там археологические па-

\footnotetext{
* Перевод с китайского выполнен С. А. Комиссаровым по авторской рукописи, работа осуществлена в рамках Плана НИР СО РАН на 2018 г., проект № 0329-2018-004.
}

Ван Пэн. Взаимодействие культур бронзового и раннего железного века Южной Сибири, Синьцзна и Северного Китая // Вестн. НГУ. Серия: История, филология. 2018. Т. 17, № 4: Востоковедение. С. 16-29.

ISSN 1818-7919

Вестник НГУ. Серия: История, фрилология. 2018. Том 17, № 4: Востоковедение

(c) Ван Пэн, 2018

(C) Комиссаров С. А., пер. с кит., 2018 
мятники, имеющие сходство с афанасьевской культурой, но также явно от нее отличающиеся. Памятники андроновской культуры (андроновской культурно-исторической общности) обнаружены как на севере, так и на юге Синьцзяна, что указывает на ее проникновение из районов Центральной Азии по нескольким основным маршрутам. Бронзовые изделия сейминско-турбинского и карасукского облика широко представлены в регионах Северного Китая и Центральной равнины (на Иньском городище). Культура верхнего слоя Сяцзядянь, распространенная на Северо-Востоке Китая, образует единое культурно-историческое пространство с культурой плиточных могил Северной Монголии и Забайкалья. Относящиеся к раннему железному веку предметы скифо-сибирского звериного стиля также широко распространены в Синьцзяне и на Севере Китая.

Однако целый ряд проблем остается нерешенным. Во-первых, погребения раннего периода могильника Чемурчек считаются самыми ранними памятниками бронзового века в Синьцзяне. О происхождении и сибирских связях этой культуры существуют различные мнения. Ряд ученых считает, что она восприняла влияние со стороны афанасьевской или окуневской культур Южной Сибири [Молодин, Алкин, 2012; Цун Дэсинь, Цзя Вэймин, 2014]. Не приходится отрицать, что по ряду признаков между ними имеется сходство, но также очевидны и существенные различия. Поэтому можно согласиться с выделением Чемурчека в особую археологическую культуру. На основе сопоставления имеющихся материалов выдвинута концепция о том, что некая группа европеоидов, двигаясь с запада на восток, одной своей ветвью достигла Минусинской котловины, где образовала афанасьевскую культуру, тогда как другая ветвь в южных отрогах Алтая дала начало чемурчекской культуре [Линь Юнь, 2011]. Что касается гипотезы А. А. Ковалева [2011] о том, что носители культуры Чемурчек пришли из западных районов Европы, то ее можно будет оценить только после привлечения гораздо большего числа доказательств.

С чемурчекской культурой тесно связаны проблемы могильников Гумугоу и Сяохэ. Поскольку они близки по географическому положению, то китайские ученые называют их памятниками культуры Сяохэ-Гумугоу и считают, что она создана чемурчекцами, которые с Алтая ушли на юг, в район оз. Лобнор. Однако поскольку на обоих могильниках не найдено керамики, то вряд ли можно однозначно утверждать, что культура Сяохэ-Гумугоу связана с чемурчекской. Мнение, что остродонные плетеные корзинки Сяохэ и остродонные керамические сосуды Чемурчека относятся к единой культурной традиции [Линь Юнь, 2011], носит предварительный характер.

Во-вторых, установлено, что андроновская культура проникла на территорию Синьцзяна из Центральной Азии по нескольким маршрутам [Шао Хуйцю, 2009]. Китайские археологи выражают сомнение в датировках, полученных российскими учеными благодаря радиоуглеродному анализу; они считают, что радиоуглерод дает более раннюю дату по сравнению с реальной, и в целом склоняются к хронологической шкале, предложенной Е. Е. Кузьминой. Они считают, что памятники андроновской культуры в Синьцзяне в основном относятся к эпохе упадка и датируются XII-IX вв. до н. э., тогда как памятников, относящихся к алакульской и федоровской культурам с датой XV-XII вв. до н. э., очень мало [Там же]. На практике серьги с раструбом андроновского облика на территории Северного Китая встречаются среди находок культуры Сыба, культуры верхнего слоя Сяцзядянь, культуры Дашэтоу (рис. 1, 1-3). Большинство ученых считает, что серьги такого вида попали на Север Китая через Синьцзян из андроновской культуры Казахстана [Линь Юнь, 2002; Шао Хуйцю, 2009]. Дата трех вышеназванных культур не позднее XVII в. до н. э., поэтому памятники андроновской культуры Синьцзяна можно удревнить до этого периода или до еще более раннего; соответственно, нет оснований сомневаться в новых радиоуглеродных датах.

Датирование андроновской культуры первой половиной II тыс. до н. э. исключает возможность ее прямого влияния на культуру Иньсюй (позднешанский период). Поэтому маловероятна гипотеза Е. Е. Кузьминой [1994; 2008; 2010], что колесницы с лошадиной запряжкой заимствованы населением Центральной равнины от одной из групп андроновцев через посредничество некой культурной общности на территории Северного Китая. Однако это не означает, что влияния андроновской культуры на шанскую не было вообще. Линь Юнь [1998] подтвердил точку зрения, высказанную А. П. Окладниковым, который считал, что бронзовые кельты енисейско-ангарского типа в зоне восточносибирской тайги представляют собой из- 
мененную форму кельтов Иньского городища. Линь Юнь сделал следующий шаг, показав, что кельты из Иньсюй, украшенные маской тао-те, являются продолжением кельтов с крестовидным узором, найденных на раннешанских памятниках в районе Чжэнчжоу (рис. 1, 4). Как считал С. В. Киселев [1960], данный вид кельтов принадлежал к андроновской культуре и отличался от бронзовых кельтов «сейминской культуры». Кельты с крестовидным узором, практически полностью аналогичные находкам из Чжэнчжоу, встречены на памятнике Наньшань в уезде Манас, Синьцзян (вместе с андроновской керамикой; материалы раскопок не опубликованы). Кроме того, ученые до сих пор не обращали внимание на то, что на некоторых памятниках Северного Китая раннешанского времени (XVI-XIV вв. до н. э.) находят керамику, украшенную узором соединенных между собой малых треугольников. Этот орнамент совершенно не похож на узор больших треугольников на керамике из Иньского городища и, вероятно, сформировался под влиянием андроновской культуры (рис. 1, 5-6). Таким образом, на основе имеющихся археологических материалов можно констатировать, что андроновская культура не только существовала на территории Синьцзяна, но и проникла дальше на восток, оказав определенное влияние на археологические культуры Северного Китая, включая культуру Шан. Однако эти влияния имели место в период, предшествующий Иньсюй (до XIV в. до н. э.).

Здесь следует рассмотреть проблему сейминско-турбинских бронз, которая пока не получила однозначного решения в российской археологии [Молодин, 2017]. Например, до конца не ясно, какие виды изделий включают сейминско-турбинские бронзы, принадлежат ли они к единой археологической культуре, какая группа или группы населения были их носителями, как они датируются, а также какие связи у них с андроновской культурой. За последние годы в Китае опубликована целая серия бронзовых копий с повернутым книзу крюком на втулке из числа новых находок или найденных ранее, но не публиковавшихся материалов. На сегодняшний день известно не менее 15 экз. таких копий (см.: [Линь Мэйцунь, 2016; Молодин, Комиссаров, Ван Пэн, 2017]). Но большая часть этих копий происходит не из археологических раскопок, поэтому нельзя определить их конкретную дату. Впрочем, и для археологических находок точную дату тоже установить трудно. Для решения проблемы проникновения сейминско-турбинских бронзовых изделий на территорию Китая необходимы дополнительные материалы из научных раскопок.

В-третьих, существует проблема взаимосвязей между карасукской и позднешанской (Иньского городища) культурами. В настоящее время многие российские и китайские археологи придерживаются мнения о том, что бронзовые изделия, сходные с иньскими, в составе карасукской культуры, большей частью относятся к каменноложскому этапу, с датой более поздней по сравнению с Иньсюй. Это исключает влияние на Шан со стороны карасукской культуры. К тому же бронзы карасукского облика в составе находок периода Иньсюй выполнены в специфическом степном стиле. Поэтому ученые КНР полагают, что некоторый набор бронзовых изделий сначала появился в регионе Северного Китая, оказал влияние на культуру Иньского городища, а затем - и на карасукскую культуру. Этим и объясняется сходство между ними [Линь Юнь, 1998]. Однако следует обратить внимание на два явления: 1) большая часть карасукских бронз Южной Сибири является случайными находками, поэтому нельзя исключить возможность того, что они происходят из карасукских могильников более раннего периода; 2) и в Шан, и в карасуке найдены так называемые модели ярма, связанные со снаряжением колесниц и лошадей [Линь Юнь, 1980; Варенов, 1984; Ван Пэн, 2015], которые внезапно появляются в рамках второго периода Иньсюй [Гао Сянпин, 2007]. Примерно в то же время столь же внезапно появляются бронзовые и керамические изделия с узорами в виде больших треугольников [Чжунго каогусюэ, 2003. С. 291] (рис. 2, 1-2). Такой орнамент также часто встречается на керамике карасукской культуры (рис. 2, 7), но очень редко в регионе Северного Китая ${ }^{1}$. С учетом этих двух положений мы можем констатировать гораздо более тесную связь между карасукской и иньской культурами, чем это считалось ранее.

\footnotetext{
${ }^{1}$ Вопрос об орнаменте из больших и малых треугольников, зафиксированном в регионах Северного Китая и Центральной равнины, чрезвычайно сложен; мы предполагаем обсудить его в специальной статье.
} 


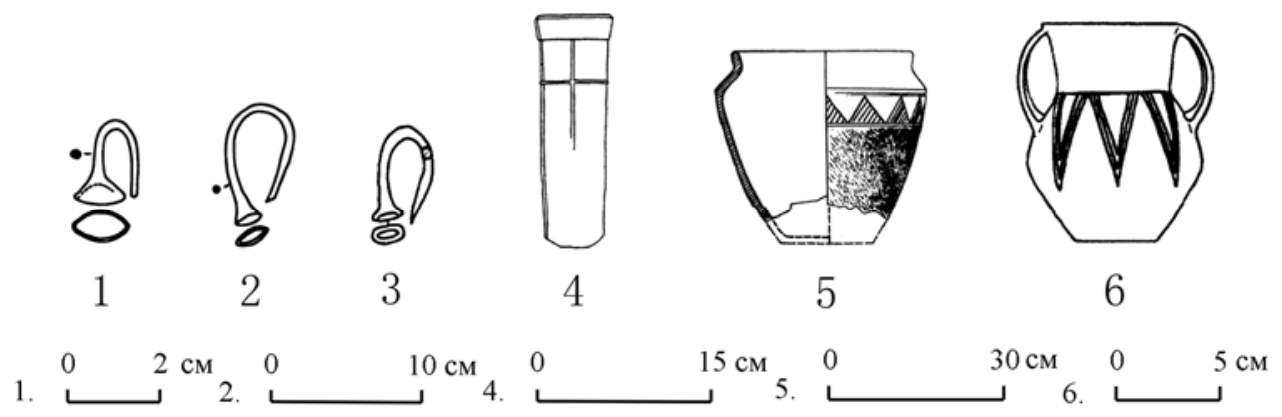

Puc. 1. Материалы, связанные с андроновской культурой, в северных районах Китая:

1, 5 - культура Дашэтоу; 2 - культура нижнего слоя Сяцзядянь; 3 - культура Сыба; 4 - культура раннего Шан; 6 - культура Цицзя. По: [Линь Юнь, 2002. С. 8, рис. 1; С. 11, рис. 5; Ян Цзяньхуа, Цзян Ган, 2008. С. 116, рис. 4; Чжунго каогусюэ.., 2003. С. 543, рис. 8-27]

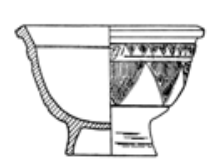

1

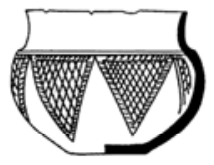

7

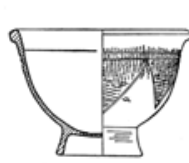

2

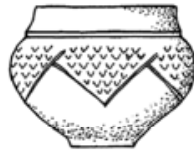

8

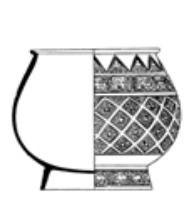

3

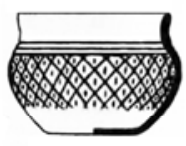

9

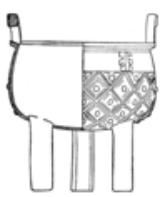

4

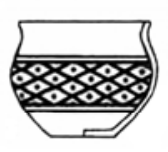

10

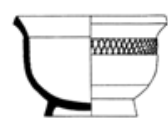

5

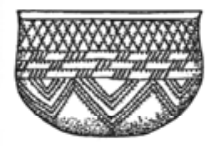

11

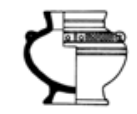

6

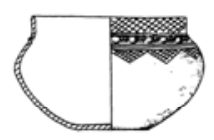

12

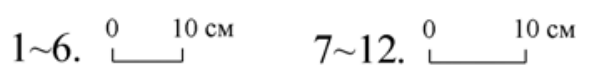

Puc. 2. Керамика и бронзовые украшения культуры Иньского городища и культур эпохи поздней бронзы Южной Сибири и Казахстана:

1-6 - культура Иньского городища; 7, 9 - карасукская культура; 8, 11 - бегазы-дандыбаевская культура; 10 - еловская культура; 12 - ирменская культура. По: [Иньсюй дэ фасянь..., 1994. С. 215, рис. 99; С. 221, рис. 103; С. 296, рис.159; Чжунго каогусюэ.., 2003. С. 407, рис. 7-9; С. 307, рис. 6-9; Поляков, 2013. С. 404, рис. 1; Варфоломеев, 2013. С. 179, рис. 6; С. 185, рис. 12; Троицкая, Новиков, 2004. С. 54, рис. 18]

На наш взгляд, орнамент на сосудах карасукской культуры (например, из соединенных вместе маленьких треугольников и т. д.) является продолжением андроновской традиции, только в первой он дополняется орнаментом из больших треугольников. Одновременно этот орнамент появляется в близких карасуку по дате и области распространения культурах: ирменской, еловской и бегазы-дандыбаевской (рис. 2, 8-11). Кроме того, следует отметить, что орнамент сетки с выступами на керамике карасукской и еловской культур (рис. 2, 9-10), а также обычный во многих археологических культурах Южной Сибири начиная с периода поздней бронзы орнамент с пересекающейся сеткой (рис. 2, 11-12) проявляется на бронзовых и керамических изделиях Иньского городища (рис. 2, 3-6). Это в основном совпадает по времени с появлением в Иньсюй узора больших треугольников и также не встречается в областях Северного Китая. Мы уверены, что эти аналогии не являются случайными. Прежде считали, что карасукская культура позднее иньской, однако результаты последних исследований показали, что хронологию карасукской и ирменской культур можно удревнить до XIV в. до н. э. [Молодин, 2008; Святко, Поляков 2009]. Поэтому возможно проводить синхронные сопоставления между южно-сибирскими культурами поздней бронзы и Иньского городища. Мы полагаем, что появление колесниц с лошадиной запряжкой, узора больших 
треугольников, орнаментов в виде сетки с выступами и пересекающихся сеток в Иньсюй связано с карасукской, ирменской, еловской и даже бегазы-дандыбаевской культурами. Эти признаки появляются в Иньсюй внезапно, а их следы в областях Северного Китая обнаруживают редко. Поэтому можно предположить, что какая-то группа людей в течение очень короткого периода времени мигрировала из Южной Сибири или Северного и Центрального Казахстана в район Иньского городища ${ }^{2}$.

В-четвертых, проблема культурного обмена в раннем железном веке, связанная с тем, что в начале I тыс. до н. э. из-за климатических изменений и ряда других причин экономика населения степной зоны Евразии стала меняться от скотоводческо-земледельческого типа к кочевому скотоводству. Усилилась подвижность населения, что привело к культурному сходству внутри больших регионов. Большинство ученых сейчас считает, что скифское искусство берет начало в разных регионах. Как указал У Энь [2002], памятники культуры верхнего слоя Сяцзядянь на Северо-Востоке Китая и Аржан-1 в Саяно-Алтайском регионе представляют собой два важных центра скифского искусства раннего периода, однако у него не было четкого мнения о характере связей между ними. Некоторые основные мотивы зафиксированного там искусства имеют удивительное сходство, например, изображения свернувшегося кольцом хищника.

Линь Юнь [2009] полагал, что этот тип украшения имеет три очага распространения (Монголия - для восточных регионов, Саяно-Алтайская область - для Центральной Азии, Причерноморье с сопредельными территориями - для западных регионов). Однако мы считаем, что формирование этого мотива в искусстве обладает значительной спецификой, поэтому, вероятно, он происходит из единого центра. Наиболее ранние изображения свернувшихся кольцом животных встречаются среди нефритовых изделий неолитической культуры Хуншань («нефритовый свино-дракон») (рис. 3, 1, 3), после чего его можно наблюдать в составе нефритовых украшений эпохи Шан-Чжоу (рис. 3, 2). Классические хуншаньские нефритовые изделия найдены в могильнике Дадяньцзы культуры нижнего слоя Сяцзядянь [Дадяньцзы..., 1996], в могиле Фу-хао на Иньском городище [Иньсюй фухао му, 1980] и в могильнике Ляндайцунь государства Жуй периода Западное Чжоу [Сунь Биньцзюнь и др., 2008] (рис. 4, 10; 3, 3). Это объясняется тем, что религиозные представления, воплотившиеся в нефритовые фигуры культуры Хуншань, были сходными и у носителей более поздних культур. Поэтому изображения свернувшихся животных в культуре Хуншань и культуре эпохи Шан-Чжоу представляют единую линию, которая, возможно, продолжалась до периода культуры верхнего слоя Сяцзядянь.

Кроме того, мы считаем, что еще одно самое сакральное и ключевое изображение в составе хуншаньских нефритов - изделие «в форме изогнутого облака» - также связано со скифским искусством. Ранее ученые полагали, что отверстия в этом изделии использовались для подвешивания, поэтому рассматривали его отверстиями кверху. Мы же считаем, что отверстия служили для того, чтобы закрепить его на навершии жезла (часть предметов имеет по два отверстия, что подтверждает нашу точку зрения). Следует рассматривать эти изделия отверстиями книзу, что позволяет показать их сходство с соответствующими предметами скифского искусства.

Все изделия «в форме изогнутого облака», обнаруженные к настоящему времени ${ }^{3}$, на основании особенностей внешнего облика можно разделить на три типа: тип А, где правая и левая стороны симметричны относительно оси (рис. 4, 1-4); тип В - правая и левая часть симметричны относительно центра (рис. 4, 6-8); тип С - упрощенный вариант первых двух типов (рис. 4, 9-14). Мы обнаружили, что их облик соответствует изображениям птицы в скифском искусстве, распространенным в Южной Сибири и Северном Китае (рис. 5),

\footnotetext{
2 Эта группа не обязательно представляла носителей карасукской, ирменской, еловской или бегазы-дандыбаевской культур, это также могли быть представители какой-либо иной, еще не известной сегодня археологической культуры. Но такая гипотетическая культура (очень вероятно, продолжение андроновской) одновременно оказала влияние на все известные культуры поздней бронзы на территории Южной Сибири и Казахстана (карасукскую, ирменскую, еловскую и бегазы-дандыбаевскую культуры).

${ }^{3}$ Согласно неполным подсчетам, опубликовано свыше 60 экз., полученных в ходе научных раскопок либо хранившихся в общественных и частных коллекциях [Люй Цзюнь, Луань Чжаопэн, 2001].
} 


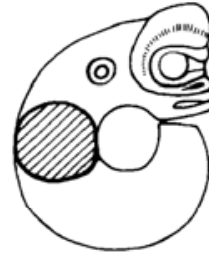

1

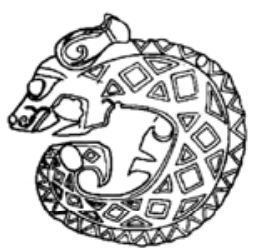

2

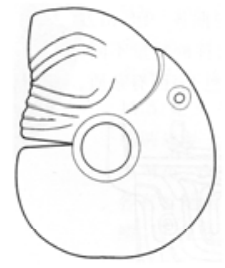

3

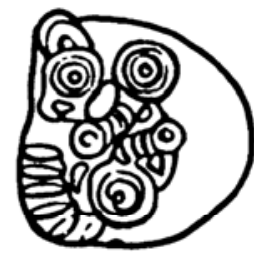

4

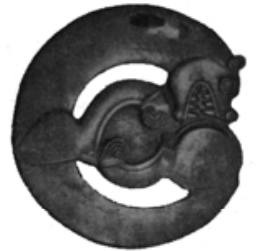

5
1,2 . $5 \mathrm{~cm}$
3. 0
$5 \mathrm{~cm}$
4.
$3 \mathrm{~cm}$
5. 0
$20 \mathrm{~cm}$

Puc. 3. Формовка фигуры свернувшегося зверя в культуре Хуншань, культуре Шан и Чжоу, культуре верхнего слоя Сяцзядянь и на памятнике Аржан-1:

1 - Насытай; 2 - могила Фу-хао; 3 - Ляндайцунь; 4 - Хэйшигоу; 5 - Аржан-1. По: [Чжу Найчэн, 2008. С. 18, рис. 3; Иньсюй дэ фасянь..., 1994. С. 346, рис. 206; Линь Юнь..., 2009.

С. 130 , рис. 1 ; Грязнов, 1980. С. 28 , рис. 15]

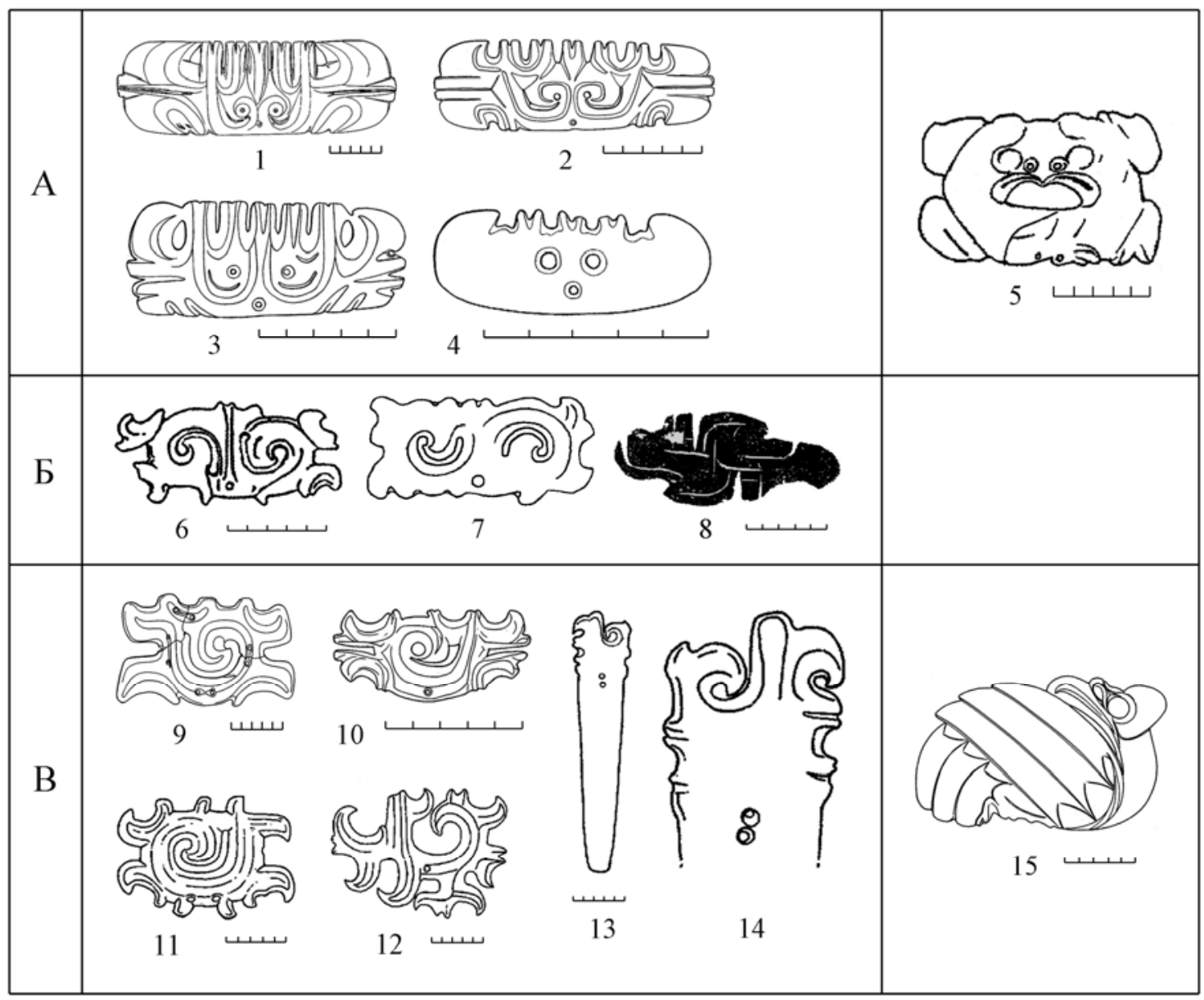

Puc. 4. Нефритовые изделия культуры Хуншань «в форме изогнутого облака» и в форме птицы:

$1-4,9,15$ - Нюхэлян; 5 - из частной коллекции в США; 6 - из Музея Гугун в Пекине; 7 - из собрания компании «Дали», Гонконг; 8 - из Музея искусств г. Тяньцзинь; 10 - Дадяньцзы; 11 - из Музея правого хошуна Балинь, Внутренняя Монголия; 12 - из Музея Гугун в Тайбэе; 13, 14 - из коллекции компании «Яндэтан». По: [Сунь Шоудао и др., 2008. С. 28, рис. 32; С. 30, рис. 34; Нюхэлян.., 2012.С. 404, рис. 71; Ду Цзиньпэн, 1998. С. 51, рис. 1; С. 53, рис. 2; С. 54, рис. 3; Дадяньцзы.., 1996. С. 174, рис. 83; Сунь Шоудао, Го Дашунь, 1984. С. 14, рис. 5; Дэн Шупин, 2002. С. 118, рис. 7] 


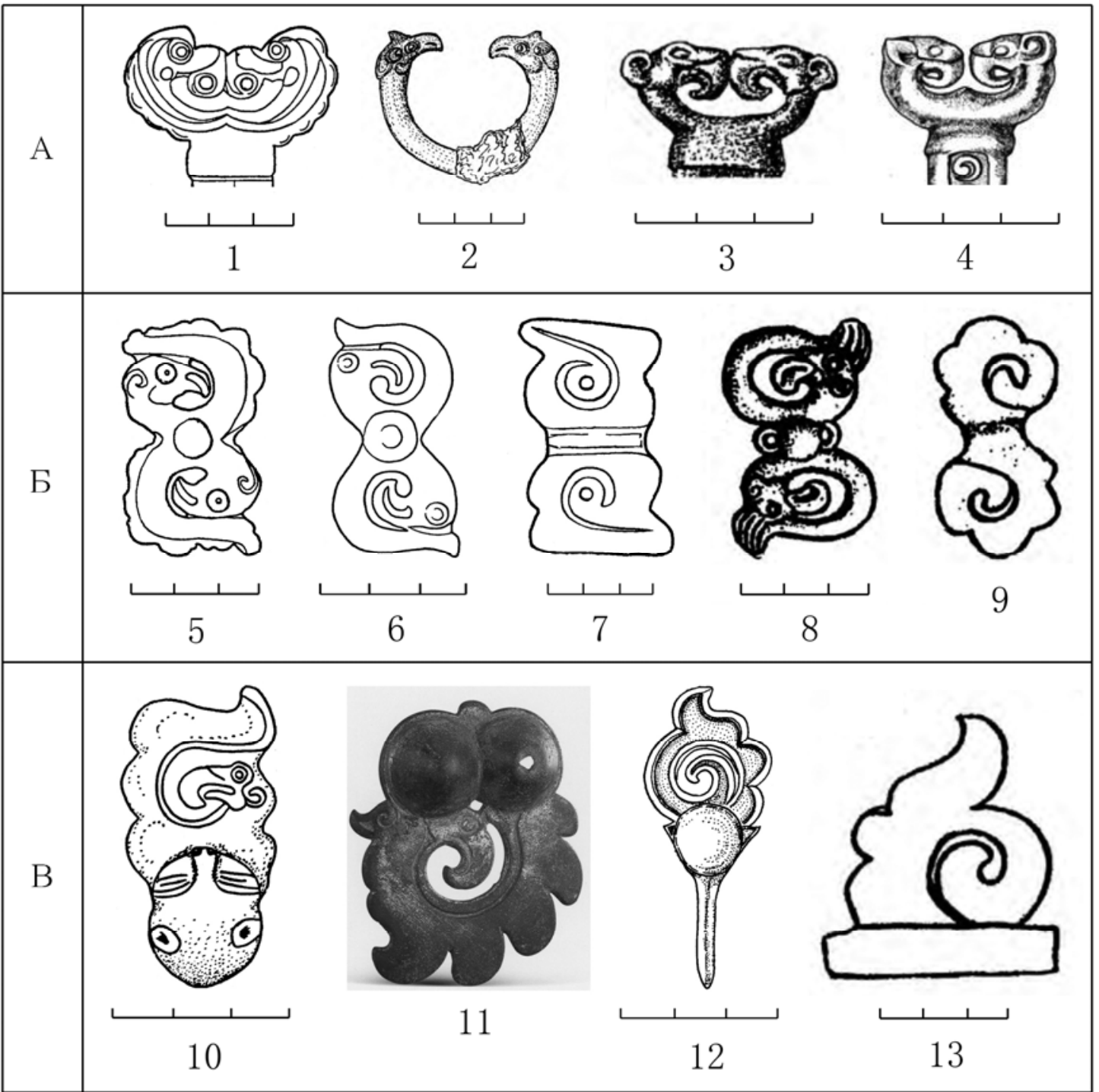

Puc. 5. Изделия в форме птицы, найденные на памятниках раннего железного века в северных районах Китая, в Южной Сибири и Казахстане:

1, 5-7, 10-12 - находки на территории Северного Китая; 2-4, 8, 9, 13 - находки на территории Южной Сибири и Казахстана. По: [Тянь Гуанцзинь, Го Сусинь, 1986. С. 5, рис. 1; С. 115, рис. 81; С. 155, рис. 110; С. 345, рис. 2; Оэрдосы цинтунци, 2006. С. 220, рис. 2; Уманский, Шамшин, Шульга, 2005. С. 177, рис. 56; С. 179, рис. 58; С. 182, рис. 61; Бейсенов, 2014. С. 103, рис. 1]

а также на бронзовых и нефритовых изделиях культур эпохи Шан-Чжоу. Поэтому можно утверждать, что хуншаньское нефриты «в форме изогнутого облака» являются ключевым элементом в построении изображений парных или одиночных птиц ${ }^{4}$. Возможно, они использовались до чжоуской эпохи (подобно нефритовому «свино-дракону»), а затем были поглощены скифским искусством. В целом можно утверждать, что области Северного Китая играли ключевую роль в происхождении скифо-сибирского звериного стиля; именно там берут начало некоторые его важные мотивы.

\footnotetext{
${ }^{4}$ Мотив парных птиц, сходных с хуншаньскими находками, очень рано появляется на территории Китая. Он распространен как в бассейне Янцзы, так и бассейне Хуанхэ.
} 
За последние годы благодаря применению научно-технических методов установлено, что обмен между культурами Востока и Запада начался не позднее, чем 4500 лет назад. Например, зооархеологи доказали, что в период от 5000 до 4000 лет назад в бассейне Хуанхэ уже появился крупный рогатый скот и мериносные овцы. Генетический анализ, выполненный по костям этих животных, показал, что у них гены коров и овец, происходивших из Западной Азии. Исследования по палеоботанике (в том числе с применением методов палеогенетики) показали, что просо и чумиза происходят из областей Северного Китая; 4500 лет назад выращивание проса уже проникает на западе в Центральную Азию, а примерно 3500 лет назад достигает Восточной Европы [Ван Вэй, 2016]. Однако объяснить возникновение подобных связей в рамках археологии пока не удалось. Столь же сложными проблемами, стоящими перед исследователями, представляется датировка и определение способа проникновения в Китай литья металлов и доместикации пшеницы. История культурных обменов между Востоком и Западом намного сложнее, чем это представляется на основе уже обнаруженных археологических материалов, но реконструкция этой истории является задачей, имманентно присущей археологии.

\section{Список литературы}

Бейсенов А. З. Кинжал с зооморфным декором сакского времени из Центрального Казахстана // Вестн. Томск. гос. ун-та. Серия: История. 2014. № 5. С. 103-107.

Варенов А. В. О функциональном предназначении «моделей ярма» эпохи Инь и Чжоу // Новое в археологии Китая. Новосибирск: Наука, 1984. С. 42-51.

Варфоломеев B. В. Керамика суперстратного облика из памятников бегазы-дандыбаевской культуры // Бегазы-дандыбаевская культура степной Евразии. Алматы: Бегазы-Тасмола, 2013. C. $167-197$.

Грязнов М. П. Аржан. Л.: Наука, 1980. 64 с.

Киселев С. В. Неолит и бронзовый век Китая // Сов. археология. 1960. № 4. С. 224-266.

Ковалев A. A. Великая чемурчекская миграция из Франции на Алтай в начале третьего тысячелетия до н. э // Рос. археол. ежегодник. 2011. №. 1 С. 183-244.

Кузьмина Е. Е. Откуда пришли индоарии? М.: Вост. лит., 1994. 464 с.

Кузьмина E. E. Классификация и периодизация памятников андроновской культурной общности. Актобе: ПринтА, 2008. 358 с.

Кузьмина E. Е. Предыстория Великого шёлкового пути. М.: КомКнига, 2010. 236 с.

Молодин В. И. Периодизация, хронология и культурная идентификация памятника Чича (Барабинская лесостепь) // Время и культура в археолого-этнографических исследованиях древних и современных обществ Западной Сибири и сопредельных территорий: проблемы интерпретации и реконструкции. Томск: Аграф-Пресс, 2008. С. 155-163.

Молодин В. И. Сейминско-турбинские проявления в Центральной Азии и Китае // Диба цзе мэнгу бэйцзяэр сиболия юй чжунго бэйфан гудай вэньхуа гоцзи сюэшу яньтаохуй: Луньвэнь тияо хуйбянь [第八届蒙古、贝加尔西伯利亚与中国北方古代文化国际学术研讨会]. Чанчунь: Цзилинь дасюэ бяньцзян каогу яньцзю чжунсинь, 2017. С. 337-347.

Молодин В. И., Алкин С. В. Памятники афанасьевского времени на северо-западе Китая (Синьцзян) // Афанасьевский сб. 2. Барнаул: Азбука, 2012. С. 149-154.

Молодин В. И., Комиссаров С. А., Ван Пэн. Бронзовые наконечники копий сейминскотурбинского типа из Китая // Tp. V (XXXI) Всерос. археологич. съезда в Барнауле - Белокурихе. Барнаул: Изд-во Алт. ун-та, 2017. Т. 1. С. 297-299.

Поляков A. B. Ранние этапы развития эпохи поздней бронзы Среднего Енисея // Бегазыдандыбаевская культура степной Евразии. Алматы: Бегазы-Тасмола, 2013. С. 401-416.

Святко С. В., Поляков А. В. Новые радиоуглеродные даты памятников эпохи бронзы - начала железного века Среднего Енисея // Роль естественно-научных методов в археологических исследованиях. Барнаул: Изд-во Алт. ун-та, 2009. С.146-149.

Теплоухов С. А. Древние погребения в Минусинском крае // Материалы по этнографии. Л., 1927. Т. 3, вып. 2. С. 57-112.

Теплоухов С. А. Опыт классификации древних металлических культур Минусинского края // Материалы по этнографии. Л., 1929. Т. 4, вып. 2. С. 41-62. 
Троицкая Т. Н., Новиков А. В. Археология Западно-Сибирской равнины: Учеб. пособие. Новосибирск: НГПУ, 2004. 136 с.

Уманский А. П., Шамшин А. Б., Шульга П. И. Могильник скифского времени Рогозиха-1 на левобережье Оби. Барнаул: Изд-во Алт. ун-та. 2005. 204 с.

Ван Вэй. Вэньхуа цзяолю юй чжунхуа вэньминдэ синчэн // Гуанмин жибао [王委鬼。文化交 流与中华文明的形成 // 光明日报]. Культурный обмен и формирование китайской цивилизации // Гуанмин жибао. 17.09.2016. С. 7. (на кит. яз.)

Ван Пэн. Цзай лунь иньчжоу гунсинцидэ юнту [王鹏。再论殷周弓形器的用途]. Еще раз об использовании инь-чжоуских изделий в форме лука // Вестн. Новосиб. гос. ун-та. Серия: История, филология. 2015. Т. 14, вып. 4: Востоковедение. С. 24-36. (на кит. яз.)

Ван Пэн, Кэмисалофу C. A. Чжунго иньцзе сулянь цзи элосы каогусюэ шупин [王朋、S.A. 科米萨罗夫。中国引介苏联及俄罗斯考古学述评]. Распространение в Китае советской и российской археологической литературы // Вестн. Новосиб. гос. ун-та. Серия: История, филология. 2013. Т. 12, вып. 4: Востоковедение. С. 45-51. (на кит. яз.)

Гао Сянпин. Люэ лунь шан-чжоу цинтун гунсинцидэ синчжи яньбянь [郜向平。略论商周 青铜弓形器的形制演变 // 华夏考古]. Обсуждение изменений формы шан-чжоуских бронзовых изделий в форме лука // Хуася каогу. 2007. № 1. С. 94-101. (на кит. яз.)

Дадяньцзы - сяцзядянь сяцэн вэньхуа ичжи юй муди фацзюэ баогао [大甸子--夏家店下层 文化遗址与墓地发掘报告]. Дадяньцзы - Отчет о раскопках поселения и могильника культуры нижнего слоя Сяцзядянь. Пекин: Кэсюэ чубаньшэ, 1996. 411 с. (на кит. яз.)

Ду Цзиньпэн. Хуншань вэньхуа «гоуюньсин» лэй юйци таньтао [杜金鹏。红山文化“勾云 形”类玉器探讨 // 考古]. Исследование и обсуждение нефритовых украшений в «форме изогнутого облака»// Каогу. 1998. № 5. С. 50-64. (на кит. яз.)

Дэн Шупин. Хуншань вэньхуа гоуюнь юй дайчи лэй юйшидэ яньцзю // Юй хунь го по чжунго гудай юйци юй чуаньтун вэньхуа сюэшу таолуньхуй вэньцзи [ 仍淑苹。红山文化勾云 与带齿类玉饰的研究 // 玉魂国魄一中国古代玉器与传统文化学术讨论会文集]. Изучение нефритовых украшений в форме изогнутого облака и с зубцами в культуре Хуншань // Дух нефрита, душа страны: Сб. работ конф. по древним нефритовым изделиям Китая в традиционной культуре. Пекин: Яньшань чубаньшэ, 2002. С. 109-127. (на кит. яз.)

Иньсюйдэ фасянь юй яньцзю [殷墟的发现与研究]. Открытия и исследования на Иньском городище. Пекин: Кэсюэ чубаньшэ, 1994. 486 с. (на кит. яз.)

Иньсюй фухао му [殷墟妇好墓]. Могила Фу-хао на Иньском городище. Пекин: Вэньу чубаньшэ, 1980. 470 с. (на кит. яз.)

Линь Мэйиунь. Сайима - туэрбинно вэньхуа цзай чжунго [林梅村。塞伊玛--图尔宾诺文化 在中国 // 考古与文物]. Сейминско-турбинская культура в Китае // Каогу юй вэньу. 2016. № 2. С. 94-101. (на кит. яз.)

Линь Юнь. Гуаньюй цинтун гунсинцидэ жогань вэньти [林沄。关于青铜弓形器的若干问 题 // 吉林大学社会科学论从 (2) ]. О некоторых вопросах бронзовых изделий в форме лука // Цзилинь дасюэ шэхуй кэсюэ луньцун. 1980. Вып. 2. С. 156-174. (на кит. яз.)

Линь Юнь. Шан вэньхуа цинтунци юй бэйфан дицюй цинтунци гуаньсичжи цзай яньцзю [林沄。商文化青铜器与北方地区青铜器关系之再研究 // 林沄学术文集]. Еще раз об исследовании связей между бронзовыми изделиями культуры Шан и бронзовыми изделиями северного региона // Сб. науч. статей Линь Юня. Пекин: Чжунго дабайкэ цюаньшу чубаньшэ, 1998. С. 262-288. (на кит. яз.)

Линь Юнь. Сядайдэ чжунго бэйфанси цинтунци [林沄。夏代的中国北方系青铜器 // 边疆 考古研究 (1) ]. Бронзовые изделия северокитайского облика при династии Ся // Бяньцзян каогу яньцзю. Пекин: Кэсюэ чубаньшэ, 2002. Вып. 1. С. 1-12. (на кит. яз.)

Линь Юнь. Лунь оуя цаоюаньдэ цзюаньцюй дунъувэнь [林法。论欧亚草原的卷曲动物纹 // 林云学术文集 (二) ]. Об узоре в форме свернувшегося зверя в степях Евразии // Сб. науч. статей Линь Юня. Пекин: Кэсюэ чубаньшэ, 2009. С. 129-142. (на кит. яз.) 
Линь Юнь. Сычоучжи лу кайтун ицянь синьцзяндэ цзяотун лусянь [林沄。丝绸之路开通 以前新疆的交通路线 // 草原文物]. Транспортные маршруты Синьцзяна до открытия Великого Шелкового пути // Цаоюань вэньу. 2011. № 1. С. 55-64. (на кит. яз.)

Люй Цзюнь, Луань Чжаопэн. Гуаньюй хуншань вэньхуа гоуюнь синлэй юйци яньцзюдэ цзигэ вэньти [吕军、奕兆鹏。关于红山文化勾云形类玉器研究的几个问题 // 文物春秋]. По поводу нескольких вопросов в изучении категории нефритовых изделий культуры Хуншань «в форме изогнутого облака» // Вэньу чуньцю. 2001. № 1. С. 8-14. (на кит. яз.)

Нюхэлян - хуншань вэньхуа ичжи фацзюэ баогао (1983-2003 няньду) [牛河梁--红山文化 遗址发掘报告（1983-2003 年度）]. Отчет о раскопках (1983-2003 гг.) Нюхэлян, памятника культуры Хуншань. Пекин: Вэньу чубаньшэ, 2012. 591 с. (на кит. яз.)

Оэрдосы цинтунци / Ван Чжихао, Ян Цзэмэн чжубянь [鄂尔多斯青铜器 / 王志浩、杨泽蒙 主编]. Ордосские бронзы / Гл. ред. Ван Чжихао, Ян Цзэмэн. Пекин: Вэньу чубаньшэ, 2006. 339 с. (на кит. яз.)

Сунь Бинщзюнь, Чэн Жуйпин, Чжсан Вэй, Чэнь Цзяньлин. Шаньси ханьчэн ляндайцунь ичжи M26 фацзюэ цзяньбао [孙秉君、程范萍、张伟、陈建凌。陕西韩城梁带村遗址 M26 发掘 简报 // 文物]. Краткий отчет о раскопках могилы M26 на памятнике Ляндайцунь， г. Ханьчэн, пров. Шэньси // Вэньу. 2008. № 1. С. 4-21. (на кит. яз.)

Сунь Шоудао, Го Дашунь. Лунь ляохэ лююйдэ юаньши вэньмин юй лундэ циюань [孙守 道、郭大顺。论辽河流域的原始文明与龙的起源 // 文物]. О первобытной цивилизации бассейна Ляохэ и происхождении [образа] дракона // Вэньу. 1984. № 6. С. 11-17. (на кит. яз.)

Сунь Шоудао, Го Дашунь, Синь Чжаньшань, Фан Дяньчунь, Чжан Кэизюй. Нюхэлян хуншань вэньхуа диэр дидянь ихао чжун шигуань удэ фацзюэ [孙守道、郭大顺、辛占山、方 殿春、张克举。牛河梁红山文化第二地点一号冢石棺墓的发掘 // 文物]. Раскопки могилы с каменным гробом, относящейся к культуре Хуншань, на кургане № 1 в пункте № 2 Нюхэлян // Вэньу. 2008. № 10. С. 15-33. (на кит. яз.)

Тань Гуанизинь, Го Сусинь. Оэрдосыши цинтунци [田广金、郭素心。鄂尔多斯式青铜器]. Бронзовые изделия ордосского типа. Пекин: Вэньу чубаньшэ, 1986. 402 с. (на кит. яз.)

У Энь. Оуя далу цаоюань цзаоци юму вэньхуадэ цзидянь сыкао [乌恩。欧亚大陆草原早期 游牧文化的几点思考 // 考古学报]. Некоторые мысли о кочевой культуре раннего этапа степной Евразии // Каогу сюэбао. 2002. № 4. С. 43-470. (на кит. яз.)

Цун Дэсинь, Цзя Вэймин. Цемуэрцекэ муди цзи ци цзаоци ицуньдэ чубу фэньси // Цинчжу

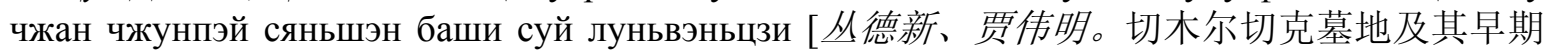
遗存的初步分析 // 庆祝张忠培先生八十岁论文集]. Могильник Чемурчек: предварительный анализ его ранних памятников // Сб. ст. к 80-летию Чжан Чжунпэя. Пекин: Кэсюэ чубаньшэ, 2014. С. 275-308. (на кит. яз.)

Чжу Найчэн. Хуншань вэньхуа шоумянь цзюэсин юйши яньцзю [朱乃诚。红山文化兽面 玦形玉饰研究 // 考古学报]. Изучение нефритовых украшений культуры Хуншань в форме подвески цзюэ с личиной зверя // Каогу сюэбао. 2008. № 1. С. 15-38. (на кит. яз.)

Чжунго каогусюэ: Ся шан цзюань [中国考古学: 夏商卷 / 杨锡璋、高伟主编]. Археология Китая: Эпоха Ся и Шан / Гл. ред. Ян Сичжан, Гао Вэй. Пекин: Чжунго шэхуй кэсюэ чубаньшэ, 2003. 668 с. (на кит. яз.)

Шао Хуйщю. Синьцзян дицюй аньдэлоново вэньхуа сянгуань ицунь таньси [邵会秋。新疆 地区安德罗诺沃文化相关遗存探析 // 边疆考古研究 (8) ]. Анализ памятников, связанных с андроновской культурой на территории Синьцзяна // Бяньцзян каогу яньцзю. Пекин: Кэсюэ чубаньшэ, 2009. Вып. 8. С. 81-97. (на кит. яз.)

Ян Цзяньхуа, Цзян Ган. Гунъюань цянь 2 цянь цзидэ цзинь шэнь гаоюань юй яньшань наньбэй [杨建华、蒋刚。公元前 2 千纪的晋陕高原与燕山南北]. Шаньси-Шэньсийское плато и территории к северу и к югу от хребта Яньшань во 2-м тыс. до н. э. Пекин: Кэсюэ чубаньшэ, 2008. 285 с. (на кит. яз.) 


\author{
Wang Peng \\ Institute of Archaeology of CASS \\ 23 Wangfujing, Beijing, China \\ kaoguwangpeng@163.com
}

\title{
INTERACTION OF BRONZE AND EARLY IRON AGE CULTURES IN SOUTH SIBERIA, XINJIANG AND NORTHERN CHINA
}

After decades of efforts by archaeologists, the general outline of the cultural exchange between South Siberia, Northern China and Xinjiang during the Bronze and early Iron Age has been clarified. There are several examples. A branch of the Europeoid population entered Xinjiang, leaving their archaeological relicts which held both some similarities to the Afanasievo culture, as well as some distinct differences. Sites of the Andronovo culture (Andronovo historical-cultural community) have been found both in the northern and the southern parts of Xinjiang, thus indicating several main routes of its penetration. Bronze items of Seima-Turbino and Karasuk appearance are wide spread in Northern China and the Central Plain (at Yinxu). The Xiajiadian upper layer culture spread in North-Eastern China (Dongbei) forms the common historical-cultural space with Slabgrave culture of Northern Mongolia and the Transbaikal region. Bronze weapons and ornaments, made in Scythian-Siberian animal style belonging to the Early Iron Age are also widespread in Xinjiang and Northern China. However, at the same time, a series of unsettled archeological issues are also gradually emerging. This article not only gives a brief summary of what has been achieved, but also puts forward our views regarding some problems. Around $2000 \mathrm{BC}$ a European population of ethnic migrants came from the West to Xinjiang and left archaeological remains there, which are represented by early burials in the Chemurchek cemetery. Andronovo culture monuments were widespread in western and central Xinjiang, and possibly further eastward, which may be reflected in relicts of cultures of the period prior to the Yin dynasty in northern China. From around 1300 BC, some ornamentations on pottery and bronze from Yinxu changed dramatically, and have great similarities with the cultures of the late Bronze Age in South Siberia and Kazakhstan. On the other hand, these factors were not found in Northern China, which shows there could be a population migration from South Siberia or northern Kazakhstan to the Central Plain in a short period of time. The fact that chariots suddenly appeared in Yinxu may be related to this. The curled animals and the shape of double and single birds on the Hongshan jades "in the form of a bent cloud" are very similar to the motifs of the Shang-Zhou culture and the art of the Scythians, their common origin shows that Northern China played an important role in the formation of the «Scythian-Siberian animal style».

Keywords: South Siberia, Northern China, Xinjiang, Bronze Age, Early Iron Age, cultural exchange.

\section{References}

Beisenov A. Z. Kinzhal s zoomorfnym dekorom sakskogo vremeni iz Tsentral'nogo Kazakhstana [A dagger of Saka period from Central Kazakhstan with zoomorphic decoration]. Vestnik of Tomsk State Univ. Series: History, 2014, no. 5, p. 103-107. (in Russ.)

Gryaznov M. P. Arzhan. Leningrad: Nauka, 1980, 64 p. (in Russ.)

Kiselev S. V. Neolit i bronzovyi vek Kitaya [Neolith and Bronze Age of China]. Sov. arkheologiya [Soviet Archaeology], 1960, no. 4, p. 224-266. (in Russ.)

Kovalev A. A. Velikaya chemurchekskaya migratsiya iz Frantsii na Altai v nachale tret'ego tysyacheletiya do $\mathrm{n}$. e [The great Chemurchek migration from France to Altai at the beginning of third millennium BC]. Ros. arkheologich. ezhegodnik [Russ. archaeological yearbook], 2011, no. 1, p. 183-244. (in Russ.)

Kuzmina E. E. Otkuda prishli indoarii? [Where Indo-Arians came from?]. Moscow, Vost. lit., 1994, 464 p. (in Russ.) 
Kuzmina E. E. Klassifikatsiya i periodizatsiya pamyatnikov andronovskoi kul'turnoi obshchnosti [Classification and periodization of Andronovo cultural community' sites]. Aktobe, PrintA, 2008, 358 p. (in Russ.)

Kuzmina E. E. Predystoriya Velikogo shelkovogo puti [Prehistory of the Great Silk road]. Moscow: KomKniga, 2010, 236 p. (in Russ.)

Molodin V. I. Periodizatsiya, khronologiya i kul'turnaya identifikatsiya pamyatnika Chicha (Barabinskaya lesostep') [Periodization, chronology and cultural identification of Chicha site (Barabinsk forest-steppe)]. Vremya $i$ kul'tura $v$ arkheologo-etnograficheskikh issledovaniyakh drevnikh $i$ sovremennykh obshchestv Zapadnoi Sibiri $i$ sopredel'nykh territorii: problemy interpretatsii i rekonstruktsii [Time and Culture in archaeology-ethnographical studies of ancient and modern societies of West Siberia and nearby territories: interpretation and reconstruction]. Tomsk, Agraf-Press, 2008, p. 155-163. (in Russ.)

Molodin V. I. Seiminsko-turbinskie proyavleniya v Tsentral'noi Azii i Kitae [The appearance of Seima-turbino phenomenon in Center Asia and China]. Diba jie menggu beijiaer xiboliya yu zhongguo beifang gudai wenhua guoji xueshu yantaohui: Lunwen tiyao huibian [The VIII Int. Academic conf. on "Ancient cultures of Mongolia, Baikal Siberia and Northern China»: Theses and synopsis compilation]. Changchun, Jilin daxue bianjiang kaogu yanjiu zhongxin, 2017, p. 337-447. (in Russ.)

Molodin V. I., Alkin S. V. Pamyatniki afanas'evskogo vremeni na severo-zapade Kitaya (Sin'tszyan) [Afanasievo Epoch sites in North-East China (Xinjiang)]. Afanas'evskii sb. 2 [On Afanasievo \{epoch\} collection-2]. Barnaul, Azbuka, 2012, p. 149-154. (in Russ.)

Molodin V. I., Komissarov S. A., Wang Peng. Bronzovye nakonechniki kopii seiminsko-turbinskogo tipa iz Kitaya [Bronze spears of Seima-Turbino type from China]. Tr. V (XXXI) Vseros. arkheologich. s"ezda v Barnaule - Belokurikhe [Proceedings of V (XXXI) All-Russian archaeological congress in Barnaul - Belokurikha]. Barnaul, Alt. Univ. Publ., 2017, vol. 1, p. 297-299. (in Russ.)

Polyakov A. V. Rannie etapy razvitiya epokhi pozdnei bronzy Srednego Eniseya [Early stages in development of the Late Bronze age at Middle of Enisey]. Begazy-dandybaevskaya kul'tura stepnoi Evrazii [Begazi-Dandybaevo Culture of steppe Eurasia]. Almaty, Begazy-Tasmola, 2013, p. 401416. (in Russ.)

Svyatko S.V., Polyakov A.V. Novye radiouglerodnye daty pamyatnikov epokhi bronzy nachala zheleznogo veka Srednego Eniseya [New radiocarbon data on the sites of Bronze Age and of the beginning of Iron Age at Middle Enisey]. Rol' estestvenno-nauchnykh metodov v arkheologicheskikh issledovaniyakh [A role of natural-science methods in archaeological investigations]. Barnaul, Alt. Univ. Publ., 2009, p.146-149. (in Russ.)

Teploukhov S. A. Drevnie pogrebeniya v Minusinskom krae [Ancient burials in Minusinsk Region]. Materialy po etnografii [Materials on ethnography]. Leningrad, 1927, vol. 3, iss. 2, p. 57112. (in Russ.)

Teploukhov S. A. Opyt klassifikatsii drevnikh metallicheskikh kul'tur Minusinskogo kraya [An attempt of classification of ancient metal cultures at Minusinsk Region]. Materialy po etnografii [Materials on ethnography]. Leningrad, 1929, vol. 4, iss. 2, p. 41-62. (in Russ.)

Troitskaya T. N., Novikov A. V. Arkheologiya Zapadno-Sibirskoi ravniny [Archaeology of West Siberian Plain]. Novosibirsk, NGPU Press, 2004, 136 p. (in Russ.)

Umanskii A. P., Shamshin A. B., Shulga P. I. Mogil'nik skifskogo vremeni Rogozikha-1 na levoberezh'e Obi [Rogozikha-1 - grave-yard of Scythian epoch at left-bank territory of Ob' River]. Barnaul, Alt. Univ. Publisher, 2005, 204 p. (in Russ.)

Varenov A. V. O funktsional'nom prednaznachenii «modelei yarma» epokhi In' i Chzhou [About functional assignment of «yoke model» of Yin and Zhou epoch]. Novoe v arkheologii Kitaya [New data in Chinese archaeology]. Novosibirsk, Nauka, 1984, p. 42-51. (in Russ.)

Varfolomeev V. V. Keramika superstratnogo oblika iz pamyatnikov begazy-dandybaevskoi kul'tury [Ceramics of super-stratum form from the sites of Begazi-Dandybaevo Culture]. Begazydandybaevskaya kul'tura stepnoi Evrazii [Begazi-Dandybaevo Culture of steppe Eurasia]. Almaty, Begazy-Tasmola, 2013, p. 167-197. (in Russ.)

Cong Dexin, Jia Weiming. Qiemuerqieke mudi ji qi zaoqi yicunde chubu fenxi. Qingzhu zhang zhongpei xiansheng bashi sui lunwenji [丛德新、贾伟明。切木尔切克墓地及其早期遗存的初步 
分析 // 庆祝张忠培先生八十岁论文集]. Qiemuerqieke cemetery and preliminary analysis of its early deposits. A collection of papers to commemorate the $80^{\text {th }}$ anniversary of Zhang Zhongpei. Beijing, Kexue chubanshe, 2014, p. 275-308. (in Chin.)

Dadianzi - xiajiadian xiaceng wenhua yizhi yu mudi fajue baogao [大甸子--夏家店下层文化遗 址与墓地发掘报告]. Dadianzi - Report on excavations of Xiajiadian lower layer culture's site and grave-yard. Beijing: Kexue chubanshe, 1996, 411 p. (in Chin.)

Deng Shuping. Hongshan wenhua gouyun yu daichi lei yushide yanjiu // Yu hun guo po zhongguo gudai yuqi yu chuantong wenhua xueshu taolunhui weji [ 邓淑苹。红山文化勾云与带齿 类玉饰的研究 //玉魂国隗一中国古代玉器与传统文化学术讨论会文集]. Investigations of Hongshan culture's nephrite dentical ornaments in form of curved cloud // Spirit of jade, soul of state: Collection of papers for conf. on ancient jades of China in traditional culture. Beijing: Yanshan chubanshe, 2002, p. 109-127. (in Chin.)

Du Jinpeng. Hongshan wenhua 《gouyunxing» lei yuqi tantao [杜金鹏。红山文化“勾云形”类 玉器探讨 // 考古]. Investigations and considerations about jades in «curved cloud form». Kaogu, 1998, no. 5, p. 50-64. (in Chin.)

Gao Xiangping. Lue lun shangzhou qingtong gongxingqide xinzhi yanbian [郜向平。略论商周 青铜弓形器的形制演变 // 华夏考古]. Discussion on the form's changes of Shang-Zhou bowshaped bronzes // Huaxia kaogu, 2007, No. 1, pp. 94-101. (in Chin.)

Lin Meicun. Saiyima-tuerbingnuo wenhua zai zhongguo [林梅村。塞伊玛--图尔宾诺文化在 中国 // 考古与文物]. Seima-Turbino culture in China. Kaogu yu wenwu, 2016, no. 2, p. 94-101. (in Chin.)

Lin Yun. Guanyu qingtong gongxingqide ruogan wenti [林沄。关于青铜弓形器的若干问题 // 吉林大学社会科学论丛 (2) ]. Several problems of bow-shaped bronzes. Jilin daxue shehui kexue luncun, 1980, iss. 2, p. 156-174. (in Chin.)

Lin Yun. Shang wenhua qingtongqi yu beifang diqu qingtongqi guanxizhi zai yanjiu // Lin yun xueshu wenji [林沄。商文化青铜器与北方地区青铜器关系之再研究 // 林法学术文集]. Once again about investigation of connection between bronzes of Shang culture and bronzes of northern region. Collection of scientific papers by Lin Yun. Beijing, Zhongguo dabaike quanshu chubanshe, 1998, p. 262-288. (in Chin.)

Lin Yun. Xiadaide zhongguo beifangxi qingtongqi [林沄。夏代的中国北方系青铜器 // 边疆考 古研究 (1) ]. Bronzes of the North China's type under the Xia Dynasty. Bianjiang kaogu yanjiu. Beijing, Kexue chubanshe, 2002, iss. 1, p. 1-12. (in Chin.)

Lin Yun. Lun ouya caoyuande juanqu dongwuwen // Lin yun xueshu wenji (2) [林沄。论欧亚 草原的卷曲动物纹 // 林云学术文集 (二) ]. On design in form of scrolled animal in Eurasian steppe. Collection of scientific papers by Lin Yun. Beijing, Kexue chubanshe, 2009, iss. 2, p. 129 142. (in Chin.)

Lin Yun. Sichouzhi lu kaitong yiqian xinjiande jiaotong luxian [林沄。丝绸之路开通以前新疆 的交通路线 // 草原文物]. Transportation routes through Xinjiang before Silk Road's opening. Caoyuan wenwu, 2011, no. 1, p. 55-64. (in Chin.)

Lü Jun, Luan Zhaopeng. Guanyu hongshan wenhua gouyun xinglei yuqi yanjiude jige wenti [ 吕 军、奕兆鹏。关于红山文化勾云形类玉器研究的几个问题 // 文物春秋]. On some problems in investigation of Hongshan culture's jades «in form of curved cloud». Wenwu chunqiu, 2001, no. 1, p. 8-14. (in Chin.)

Niuheliang - hongshan wenhua yizhi fajue baogao (1983-2003 niandu) [牛河梁--红山文化遗址 发掘报告（1983-2003 年度）]. Report on excavations (1983-2003 years) of Niuheliang, Hongshan culture's site. Beijing, Wenwu chubanshe, 2012, 591 p. (in Chin.)

Oerduosi qingtongqi / Wang Zhihao, Yang Zemeng zhubian [鄂尔多斯青铜器 / 王志浩、杨泽 蒙主编]. Ordos bronzes / Ed. by Wang Zhihao, Yang Zemeng. Beijing, Wenwu chubanshe, 2006, 339 p. (in Chin.)

Shao Huiqiu. Xinjiang diqu andeluonuowo wenhua xianguan yicun tanxi [邵会秋。新疆地区安 德罗诺沃文化相关遗存探析 // 边疆考古研究 (8) ]. Analysis of the materials connected with 
Andronovo Culture in Xinjiang. Bianjiang kaogu yanjiu. Beijing, Kexue chubanshe, 2009, iss. 8, p. 81-97. (in Chin.)

Sun Bingjun, Cheng Ruiping, Zhang Wei, Chen Jianling. Shaanxi hancheng liangdaicun yizhi M26 fajue jianbao [孙秉君、程荵萍、张伟、陈建凌。陕西韩城梁带村遗址 M26 发掘简报 // 文物]. Brief report about excavations of burial M26 at Liangdaicun, Hancheng town, Shaanxi province. Wenwu, 2008, no. 1, p. 4-21. (in Chin.)

Sun Shoudao, Guo Dashun. Lun liaohe liuyude yanshi wenming yu longed qiyuan [孙守道、郭 大顺。论辽河流域的原始文明与龙的起源 // 文物]. About Liaohe Basin primitive civilization and origin of dragon image. Wenwu, 1984, no. 6, p. 11-17. (in Chin.)

Sun Shoudao, Guo Dashun, Xin Zhanshan, Fang Dianchun, Zhang Keju. Niuheliang hongshan wenhua dier didian yihao zhong shiguan mude fajue [孙守道、郭大顺、辛占山、方殿春、张克 举。牛河梁红山文化第二地点一号冢石棺墓的发掘//文物]. Excavations of Hongshan culture's burial with stone coffin at the mound No. 1 in the point No. 2 in Niuheliang. Wenwu, 2008, no. 10, p. 15-33. (in Chin.)

Tian Guangjin, Guo Suxin. Oerduosi qingtongqi [田广金、郭素心。鄂尔多斯式青铜器]. Bronzes of Ordos style. Beijing: Wenwu chubanshe, 1986, 402 p. (in Chin.)

Wang Peng. Zai lun yinzhou gongxingqide yongtu [王鹏。再论殷周弓形器的用途]. Once again about using of bow-shaped dronzes of Yin and Zhou. Vestnik of Novosib. State Univ. Series: History, philology, 2015, vol. 14, iss. 4: Oriental Studies, p. 24-36. (in Chin.)

Wang Peng, S. A. Kemisaluofu. Zhongguo yinjie sulian ji eluosi kaoguxue shuping [王鹏、S.A. 科米萨罗夫。中国引介苏联及俄罗斯考古学述评]. Dissemination of the Soviet and Russian archaeological literature in China. Vestnik of Novosib. State Univ. Series: History, philology, 2013, vol. 12, iss. 4: Oriental Studies, p. 45-51. (in Chin.)

Wang Wei. Wenhua jiaoliu yu zhonghua wenmingde xincheng [王巍。文化交流与中华文明的 形成 // 光明日报]. Cultural exchange and formation of Chinese civilization. Guangming ribao, 17.09.2016, p. 7. (in Chin.)

Wu En. Ouya dalu caoyuan zaoqi youmu wenhuade jidian sikao [乌恩。欧亚大陆草原早期游 牧文化的几点思考 // 考古学报]. Some ideas about nomadic culture of early stage in steppe Eurasia. Kaogu xuebao, 2002, no. 4, p. 43-470. (in Chin.)

Yang Jianghua, Jiang Gang. Guanyu qian erqian jide jin shen gaoyuan yu yanshan nanbei [杨建 华、蒋刚。公元前 2 千纪的晋陕高原与燕山南北]. Shanxi-Shenxi Plato and territories on both, northern and southern, sides of Yanshan ridge in $2^{\text {nd }}$ Millennium BC. Beijing, Kexue chubanshe, 2008, 285 p. (in Chin.)

Yinxude faxian yu yanjiu [殷墟的发现与研究]. Discoveries and investigations on Yin xu. Beijing, Kexue chubanshe, 1994, 486 p. (in Chin.)

Yinxu fuhao mu [殷墟妇好墓]. The tomb of Fu-hao at Yin xu. Beijing, Wenwu chubanshe, 1980, 470 p. (in Chin.)

Zhongguo kaoguxue: Xia shang juan [中国考古学: 夏商卷 / 杨锡璋、高伟主编]. Archaeology of China: Xia and Shang epoch. Ed. by Yang Xizhang, Gao Wei. Beijing, Zhongguo shehui kexue chubanshe, 2003, 668 p. (in Chin.)

Zhu Naicheng. Hongshan wenhua shoumian juexing yushi yanjiu [朱乃诚。红山文化兽面玦形 玉饰研究 // 考古学报]. Investigation of Hongshan culture's nephrite ornaments in form of juependants with animal mask. Kaogu xuebao, 2008, no. 1, p. 15-38. (in Chin.) 